\title{
PENGEMBANGAN MODUL PEMBELAJARAN MATEMATIKA BERBASIS ETNOMATEMATIKA BERBANTUAN WINGEOM BERDASARKAN LANGKAH BORG AND GALL
}

\author{
Luthvia Rohmaini ${ }^{1}$, Netriwati ${ }^{2}$, Komarudin 3 , Fadly Nendra4 ${ }^{4}$, Maratul Qiftiyah ${ }^{5}$ \\ 1,2,3,4 Universitas Islam Negeri Raden Intan Lampung, Jl. Let. Kol. H. Endro Suratmin, Lampung, Indonesia \\ 5 Universitas Islam Negeri Sunan Kalijaga Yogyakarta, Jl. Laksda Adisucipto, Sleman, Yogyakarta, Indonesia \\ Email: luthvia.rohmaini20@gmail.com
}

\begin{abstract}
The purpose of this research is to find out how to develop Wingeom-assisted ethnomathematics-based mathematical learning modules on curved side space building materials. This type of research uses Research and Development (R\&D) using borg and gall models. Sampling technique using simple random sampling, namely class IX-D MTs.N 2 Bandar Lampung numbered 40 students and class IX-1 MTs Mathla'ul Anwar Gisting numbered 32 students. Data collection techniques use interviews, observations, and questionnaires. The data analysis test used is a qualitative descriptive analysis, which describes the development results of the product. The results of the study conducted on the validation test obtained an average percentage score of $78 \%$ with the criteria "worthy" by the material expert, $86 \%$ with the criteria "very feasible" by the media expert, and $87 \%$ with the criteria "very feasible" by the language expert. Meanwhile, the response of students earned an average percentage of $82 \%$ with the category "very interesting". Product trials were conducted on a small and large scale, obtaining an average percentage of $79.72 \%$ with the category "very interesting". The results of this study show that the learning modules developed have decent/valid criteria and are interesting to use as a learning resource in math learning.
\end{abstract}

Keywords: Borg and Gall, ethnomathematics, mathematics learning, wingeom

\begin{abstract}
ABSTRAK
Tujuan dari penelitian ini adalah mengetahui cara mengembangkan modul pembelajaran matematika berbasis etnomatematika berbantuan Wingeom pada materi bangun ruang sisi lengkung. Jenis penelitian ini menggunakan Research and Development (R\&D) dengan menggunakan model Borg and Gall. Teknik pengambilan sampel menggunakan simple random sampling, yaitu kelas IX-D MTs.N 2 Bandar Lampung berjumlah 40 peserta didik dan kelas IX-1 MTs Mathla'ul Anwar Gisting berjumlah 32 peserta didik. Teknik pengumpulan data menggunakan wawancara, observasi, dan angket (kuesioner). Uji analisis data yang digunakan adalah analisis deskriptif kualitatif, yaitu menjabarkan hasil pengembangan dari produk. Hasil penelitian yang dilakukan pada uji validasi memperoleh skor persentase rata-rata $78 \%$ dengan kriteria "layak" oleh ahli materi, 86\% dengan kriteria "sangat layak" oleh ahli media, dan 87\% dengan kriteria "sangat layak" oleh ahli bahasa. Sedangkan respon peserta didik memperoleh persentase rata-rata sebesar $82 \%$ dengan kategori "sangat menarik". Uji coba produk dilakukan pada skala kecil dan skala besar, diperoleh persentase rata-rata $79,72 \%$ dengan kategori "sangat menarik". Hasil penelitian ini menunjukkan bahwa modul pembelajaran yang dikembangkan memiliki kriteria layak/valid dan menarik untuk digunakan sebagai sumber belajar dalam pembelajaran matematika.
\end{abstract}

Kata kunci: Borg and Gall, etnomatematika, modul pembelajaran, wingeom

Dikirim: 15 Juli 2020; Diterima: 29 Agustus 2020; Dipublikasikan: 30 September 2020

Cara sitasi: Rohmaini, L., Netriwati, Komarudin, Nendra, F., \& Qiftiyah, M. (2020). Pengembangan modul pembelajaran matematika berbasis etnomatematika berbantuan wingeom berdasarkan langkah borg and gall. Teorema: Teori dan Riset Matematika, 5(2), 176-186. 


\section{PENDAHULUAN}

Pembelajaran matematika merupakan unsur yang sangat penting dalam pembelajaran di jenjang pendidikan dasar dan menengah. Proses pembelajaran matematika untuk mencapai suatu tujuan yang diinginkan tentunya harus memiliki fasilitas, materi, motivasi dan kreatifitas dalam proses pembelajaran (Srimaya, 2017). Seperti fasilitas motivasi misalnya dengan menggunakan metode, bahan ajar yang lebih menarik yang sesuai dengan materi pelajaran sehingga akan lebih mudah dipahami (Cicilia \& Vebrianto, 2020; Hidayat et al., 2020).

Diketahui bersama bahwa kondisi di lapangan belum adanya bahan ajar yang tepat sehingga membutuhkan bahan ajar berupa modul yang dapat membuat lebih mudah memahami materi (Serena et al., 2020; Irmayanti \& Suryani, 2020; Harista \& Rukun, 2020; Yustiana \& Kusumadewi, 2020). Peserta didik juga masih mengalami kesulitan dalam belajar baik secara mandiri maupun tidak (Subekti \& Suparman, 2020; Abdurohman et al., 2020).

Hasil kemampuan dari peserta didik ini tergantung pada kondisi saat berlangsungnya kegiatan pembelajaran. Banyak faktor yang mempengaruhi kemampuan peserta didik salah satunya adalah bahan ajar yang digunakan. bahan ajar yang menarik sangat dibutuhkan oleh peserta didik yang dapat memudahkan untuk mengingat materi pembelajaran (Hasanah \& Indrawati 2020). Berdasarkan ungkapan diatas maka perlu dikembangkannya bahan ajar matematika berupa modul pembelajaran. Data penelitian mengenai bahan ajar dan penelitian mengenai pembelajaran yang menggunakan pendekatan etnomatematika pada 4 tahun terakhir disajikan pada Gambar 1.

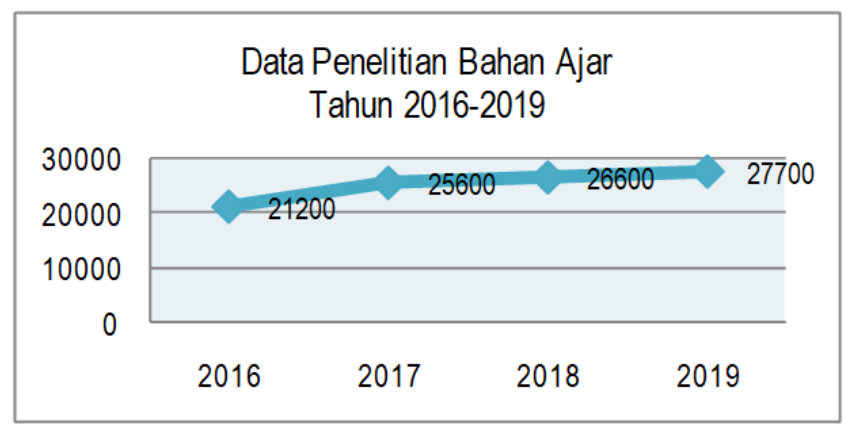

Gambar 1. Data penelitian bahan ajar tahun 2016-2019

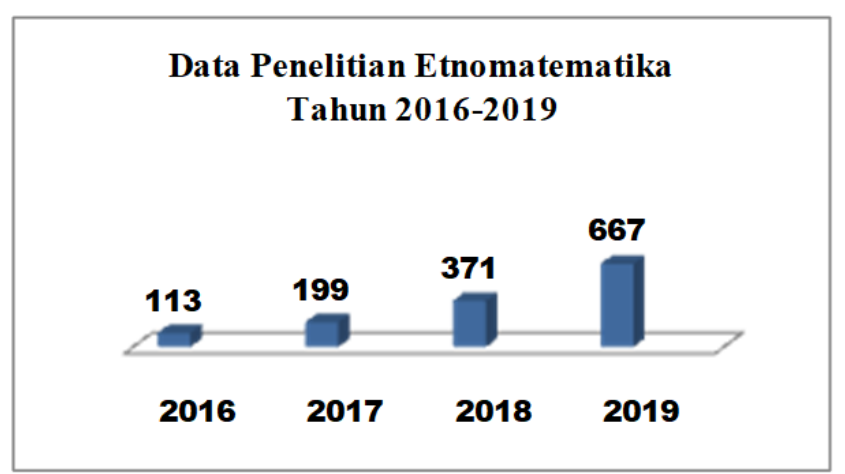

Gambar 2. Data penelitian etnomatematika tahun 2016-2019

Berdasarkan Gambar 1 dan Gambar 2 merupakan jumlah penelitian yang berkaitan dengan bahan ajar dan etnomatematika yang terindeks pada google scholar setiap tahun. Penelitian yang dilakukan oleh peneliti sebelumnya terus meningkat setiap tahunnya. Hal ini menunjukkan bahwa setiap tahun dibutuhkan pengembangan bahan ajar yang berbasis etnomatematika (Aprilianti et al., 2019; Nugroho et al., 2019). Menurut Rifqi dalam bukunya bahwa pengembangan adalah suatu proses perubahan dari yang kurang baik menjadi lebih baik dari yang sebelumnya (Amin, 2015). Modul merupakan bahan ajar yang memudahkan peserta didik dalam proses pembelajaran karena peserta didik dapat belajar secara mandiri maupun dengan bimbingan pendidik (Setiyadi, 2017; Saputra et al., 2019). Materi yang terdapat pada modul dapat terkonsep dan sangat mudah dipahami oleh peserta didik (Diana et al., 2018). 
Modul pembelajaran merupakan bahan ajar yang dirancang secara sistematis didasari dengan kurikulum yang berlaku dan dikemas kedalam bentuk satuan pembelajaran serta dapat dipelajari secara mandiri oleh pembaca dalam satuan waktu tertentu (Purwanto, 2007). Etnomatematika merupakan suatu cara untuk digunakan dalam penggunaan ilmu matematika yang berkaitan dengan ilmu kearifan lokal dan dapat dimanfaatkan guna mempermudah jalan pikir seseorang (Laurens, 2010). Dalam penelitian ini budaya yang digunakan adalah budaya Lampung, dimana materi bangun ruang sisi lengkung dikaitkan dengan budaya-budaya Lampung seperti bentuk tabung yang menyerupai gendang. Modul pembelajaran matematika berbasis etnomatematika sudah banyak dibahas oleh peneliti sebelumnya. Maryati \& Suparman (2018) dalam penelitiannya menjelaskan bahwa pada proses pembelajaran guru belum mengajak peserta didik untuk dapat berpikir memecahkan masalah, mengusulkan penyelesaian atau solusi dan peserta didik cenderung pasif (Sani, 2019). Berdasarkan hal tersebut, perlu dikembangkannya media dalam membantu siswa menghubungkan ide-ide matematik (Nurhayati, et al., 2020), serta bahan ajar yang inovatif dan kreatif dengan menggunakan pendekatan etnomatematika yang dapat menarik peserta didik dalam proses belajar (Fajar et al., 2018; Setiawan et al., 2018), serta dapat membangkitkan peserta didik dalam berpikir dan menggali informasi (Prabawa \& Zaenuri 2017; Marsigit et al., 2018). Penelitian tentang bahan ajar etnomatematika juga telah dilakukan oleh (Nurafni et al., 2020). Adapun pembahasan mengenai Wingeom pada penelitian sebelumnya juga sudah diteliti Pinahayu et al. (2018), dan Firmasari et al. (2013).

Berdasarkan ungkapan yang telah diuraikan dan data yang didapat mengatakan bahwa peserta didik membutuhkan sebuah bahan ajar yang menarik dan memudahkan dalam mengingat materi serta membuat peserta didik lebih termotivasi dalam proses belajar yaitu dengan mengembangkan bahan ajar matematika berupa modul pembelajaran matematika berbasis etnomatematika berbantuan Wingeom pada materi bangun ruang sisi lengkung.

\section{METODE PENELITIAN}

Metode penelitian yang digunakan dalam penelitian ini yaitu Research and Development (R\&D) dengan menggunakan model Borg and Gall. Dalam penelitian pengembangan ini menggunakan langkahlangkah Borg and Gall yang memiliki 10 langkah penelitian (Haryati 2012), disajikan pada Gambar 3.

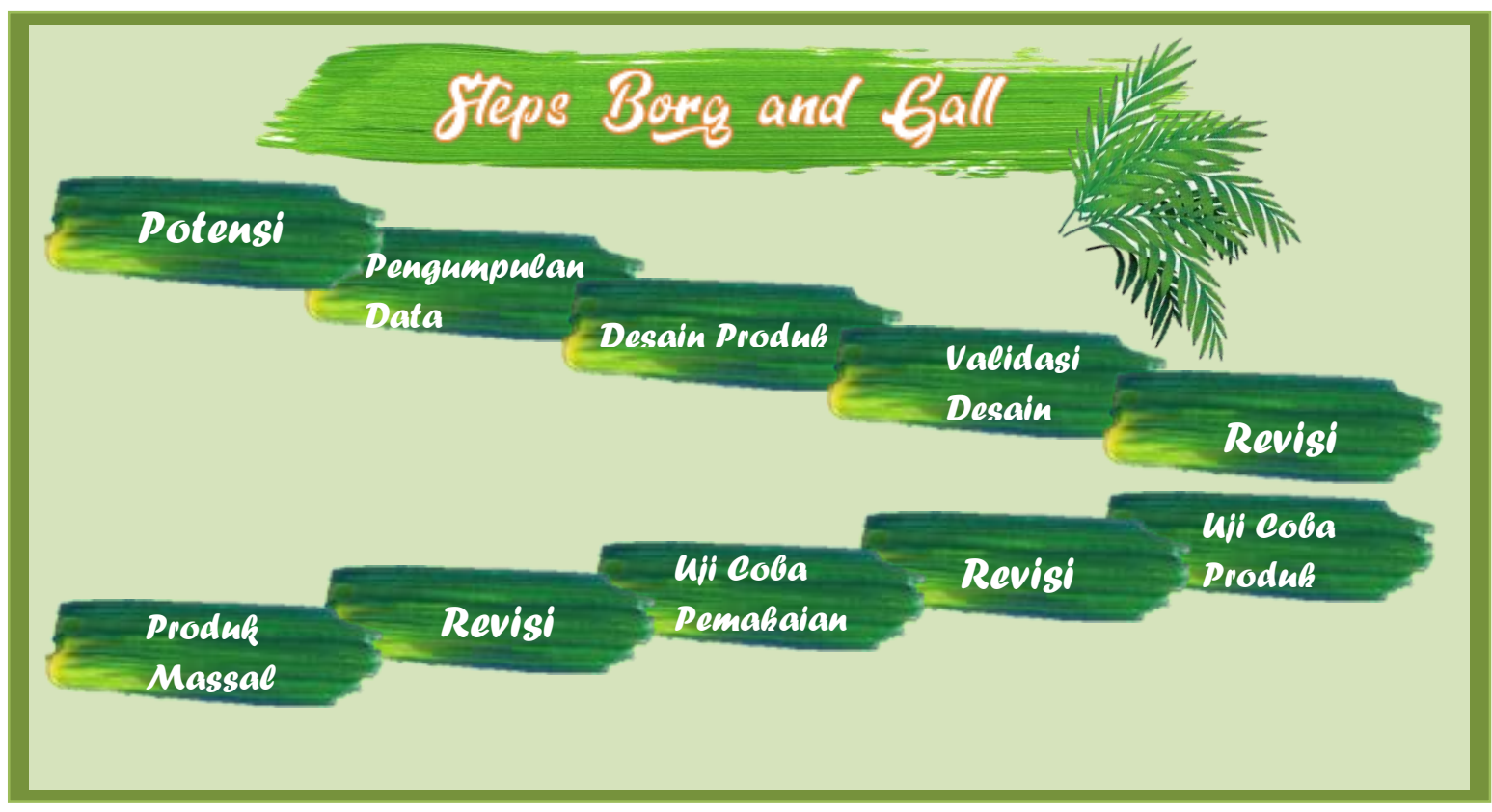

Gambar 3. Langkah-langkah Borg and Gall

Teknik pengambilan sampel menggunakan simple random sampling diperoleh dua kelas, yaitu kelas IX-D di MTs.N 2 Bandar Lampung dengan jumlah 40 peserta didik dan kelas IX-1 di MTs Mathla'ul Anwar Gisting dengan jumlah 32 peserta didik. Selanjutnya 6 peserta didik dari masing- 
masing sekolah merupakan responden skala kecil dari modul yang dikembangkan, sedangkan sisanya merupakan responden skala besar. Teknik pengumpulan data menggunakan wawancara, observasi dan angket (kuesioner). Uji analisis data yang digunakan adalah analisis deskriptif kualitatif, yaitu menjabarkan hasil pengembangan dari produk. Penelitian yang dilakukan akan menghasilkan sebuah produk akhir dengan bentuk modul pembelajaran matematika berbasis etnomatematika berbantuan Wingeom pada materi bangun ruang sisi lengkung. Penskoran dalam validasi menggunakan kriteria Nisa \& Agung (2014) yang disajikan pada Tabel 1.

Tabel 1. Skala penilaian validasi ahli

\begin{tabular}{cc}
\hline Kategori & Bobot Nilai \\
\hline Sangat Baik & 4 \\
Baik & 3 \\
Kurang Baik & 2 \\
Sangat Kurang Baik & 1 \\
\hline
\end{tabular}

Selanjutnya, rumus yang digunakan dalam setiap pertanyaan menggunakan rumus berikut Anas (2015).

$$
\mathrm{P}=\frac{f}{N} \times 100 \%
$$

Keterangan:

$\mathrm{P}$ : Angka persentase dari data angket

$\mathrm{N}$ : Banyaknya skor maksimum

$f$ : Banyaknya skor didapat

Langkah terakhir yaitu hasil dari perhitungan angka dari persentase sebuah data angket yang didapat, dicocokkan dengan Tabel 2 (Sedarmayanti et al., 2002).

Tabel 2. Kriteria validasi

\begin{tabular}{cc}
\hline Skor & Kriteria \\
\hline $80 \%<\mathrm{P} \leq 100 \%$ & Sangat Layak \\
$60 \%<\mathrm{P} \leq 80 \%$ & Layak \\
$40 \%<\mathrm{P} \leq 60 \%$ & Cukup Layak \\
$20 \%<\mathrm{P} \leq 40 \%$ & Kurang Layak \\
$0 \% \leq \mathrm{P} \leq 20 \%$ & Sangat Kurang Layak \\
\hline
\end{tabular}

\section{HASIL DAN PEMBAHASAN}

Pengembangan dari penelitian ini menghasilkan sebuah modul pembelajaran matematika berbasis etnomatematika berbantuan Wingeom pada materi bangun ruang sisi lengkung. Berdasarkan penelitian dan pengembangan yang telah dilakukan sesuai dengan prosedur penelitian Borg and Gall terdapat 10 langkah penelitian. Tahap pertama adalah potensi dan masalah, masalah yang terdapat di lapangan adalah dalam pembelajaran matematika peserta didik masih merasa kesulitan dalam memahami materi (Umam 2019), dan merasa bosan sehingga peserta didik pasif dalam proses pembelajaran (Mulyani 2016), pendidik juga belum menggunakan bahan ajar yang membuat peserta didik tertarik (Rizki 2019). Potensi yang diperoleh adalah fasilitas sekolah sudah sangat memadai dan peserta didik sudah memiliki smartphone serta hampir keseluruhan membawanya ke sekolah. Sehingga penulis memanfaatkan penggunaan teknologi (software komputer atau smartphone android) dalam pembelajaran matematika, salah satunya yaitu etnomatematika dan Wingeom dapat mendorong peserta didik untuk belajar dan mempermudah peserta didik dalam memahami materi pelajaran matematika khususnya materi bangun ruang sisi lengkung (Tjiptiany et al., 2016).

Tahap kedua mengumpulkan berbagai informasi yang berkaitan dengan bahan ajar atau media yang menunjang. Peneliti menggunakan sumber-sumber sebagai referensi disajikan pada Tabel 3. 
Tabel 3. Referensi modul

\begin{tabular}{|c|c|c|}
\hline No. & Judul buku & Pengarang \\
\hline 1. & Matematika untuk SMP/MTs Kelas IX Semester 2 & $\begin{array}{l}\text { Subchan, Winarni, Lukman Hanafi, M. Syifa'ul Mufid, } \\
\text { Kistosil Fahim, Wawan Hafid Syaifuddin dan Sari } \\
\text { Cahyaningtias. }\end{array}$ \\
\hline 2. & Matematika Semester 2 Untuk SMP Kelas IX & M.Cholik Adinawan \\
\hline 3. & Matematika untuk SMP dan MTs Kelas IX & Linda Kusumawardani dan Setia Budhi \\
\hline 4. & Mudah Belajar Matematika untuk Kelas IX SMP/MTs & Nuniek Avianti Agus \\
\hline 5. & $\begin{array}{l}\text { Mandiri Mengasah Kemampuan Diri Matematika untuk } \\
\text { SMP/MTs Kelas IX }\end{array}$ & Kurniawan \\
\hline
\end{tabular}

Tahapan pertama yaitu potensi \& masalah serta tahapan kedua yaitu mengumpulkan data/ informasi telah selesai dilakukan maka selanjutnya adalah mendesain produk. Setelah produk selesai didesain, hal yang dilakukan adalah penilaian oleh para ahli. Dilakukannya penilaian para ahli ini agar produk yang dikembangkan mencapai tujuan yang diinginkan (Zakiy et al., 2018). Validasi desain pada modul pembelajaran ini diuji oleh 6 validator ahli yaitu 3 ahli materi, 2 ahli media dan 1 ahli bahasa. Penilaian validasi ahli materi dianalisis 3 aspek yaitu aspek kelayakan isi, kelayakan kegrafikan, dan kelayakan bahasa.

Hasil uji validasi oleh ahli materi disajkan pada Gambar 4.

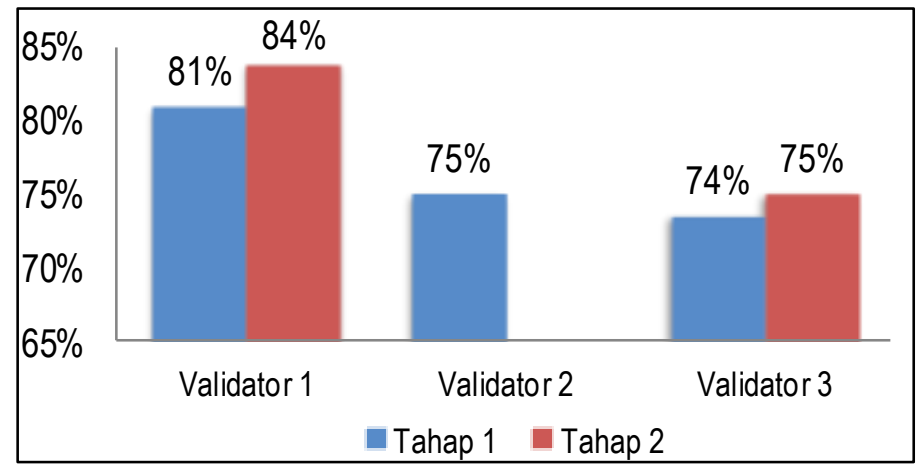

Gambar 4. Hasil uji validasi oleh ahli materi

Berdasarkan Gambar 4 bahwa hasil yang diperoleh dari validasi para ahli materi diperoleh rata-rata $78 \%$ dengan kriteria "Layak". Pada validasi ahli materi oleh validator kedua hanya melakukan satu tahapan saja karena pada tahap pertama menurut validator modul yang dikembangkan sudah memenuhi kriteria sehingga tahapan validasi ahli materi dilanjutkan ke validator selanjutnya. Pada penelitian Zakiy et al. (2018) yang menyatakan bahwa hasil validasi ahli materi modul yang dikembangkannya mendapat skor rata-rata 3,67 dengan kriteria valid. Hal ini senada dengan penelitian sebelumnya yang menyatakan bahwa produk yang dikembangkan mendapatkan kriteria valid atau layak (Utami et al., 2018; Khalimah et al., 2017). Adapun hasil validasi oleh ahli media tersedia pada Gambar 5.

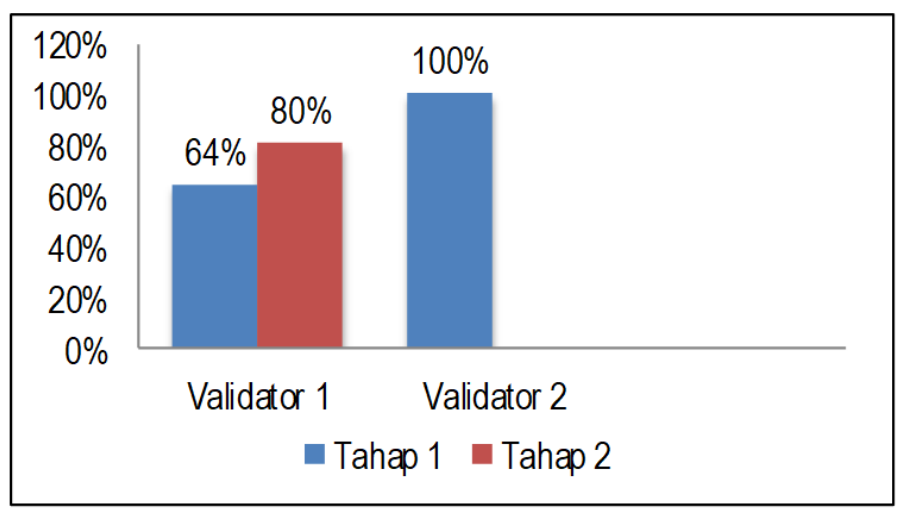

Gambar 5. Hasil uji validasi oleh ahli media 
Berdasarkan Gambar 5 hasil validasi oleh ahli media mendapatkan persentase sebesar $65 \%$ para tahap 1 dan $80 \%$ pada tahap 2. Hasil validasi ahli media oleh validator 2 memperoleh persentase $100 \%$. Sehingga hasil validasi ahli media memperoleh persentase rata-rata sebesar $86 \%$ dengan kriteria "Sangat Layak". Hal ini diperkuat oleh penelitian sebelumnya yang mendapatkan kriteria layak pada hasil uji validasi ahli media yang dilakukan (Nelawati et al., 2018; Pratami et al., 2018; Pradipta \& Hernawati 2015). Hasil validasi oleh ahli bahasa disajikan pada Gambar 6.

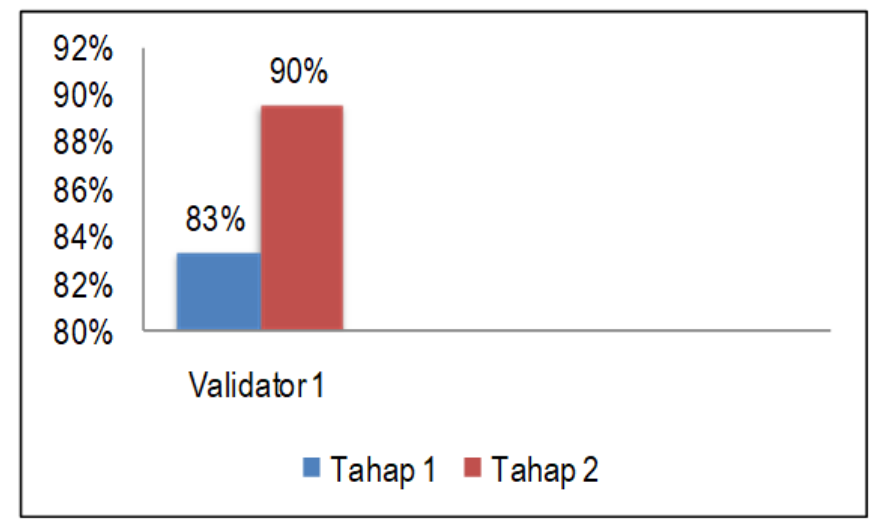

Gambar 6. Hasil uji validasi oleh ahli bahasa

Berdasarkan Gambar 6 hasil validasi ahli bahasa pada modul pembelajaran matematika berbasis etnomatematika berbantuan Wingeom pada materi bangun ruang sisi lengkung memperoleh persentase rata-ratanya $87 \%$ dengan kriteria sangat layak. Hal ini juga diperkuat oleh penelitian yang dilakukan oleh peneliti sebelumnya yang menunjukkan bahwa modul atau bahan ajar yang dikembangkan mendapatkan kriteria layak (Sukri et al., 2017; Prasetya 2012; Hidayati 2016). Keterbaruan penelitian ini dengan penelitian sebelumnya adalah bahwa modul pembelajaran matematika berbasis etnomatematika berbantuan Wingeom pada materi bangun ruang sisi lengkung memiliki kategori sangat layak pada uji validasi oleh ahli media dan bahasa.

Berdasarkan validasi oleh ahli materi, ahli media, dan ahli bahasa maka modul pembelajaran ini layak sebagai bahan ajar dalam pembelajaran matematika. Kelayakan modul ini tentunya tak terlepas dari bimbingan, masukan dan saran para ahli. Setelah modul sudah divalidasi dan revisi sesuai dengan masukan dan saran validator, maka modul siap melakukan uji coba produk. Uji coba produk untuk meyakinkan modul pembelajaran yang didasari dengan respon peserta didik berikan. Adapun respon yang diberikan adalah keantusiasan dan sangat tertarik dengan modul pembelajaran matematika berbasis etnomatematika berbantuan Wingeom (Sari et al., 2018; Wijayanto 2017; Disnawati \& Nahak 2019). Hasil disajikan pada Tabel 4.

Tabel 4. Hasil uji kemenarikan

\begin{tabular}{ccc}
\hline No. & Asal Sekolah & Persentase (\%) \\
\hline 1. & MTs N 2 Bandar Lampung & $78,24 \%$ \\
2. & MTs Mathla'ul Anwar Gisting & $81,21 \%$ \\
& Persentase Rata-rata (\%) & $79,72 \%$ \\
\multicolumn{2}{c}{ Kriteria } & Sangat Menarik \\
\hline
\end{tabular}

Berdasarkan Tabel 4 di atas menunjukkan bahwa pada uji coba produk memperoleh persentase rata-rata 79,72\% dengan kriteria "Sangat Menarik". Uji kemenarikan dilakukan dengan 2 tahap yaitu uji coba produk dengan skala kecil dan uji coba produk dengan skala besar. Pada uji coba produk skala kecil memperoleh skor persentase rata-rata sebesar $82 \%$ dengan kriteria "Sangat Layak". Hal ini didukung oleh penelitian sebelumnya yang juga mendapatkan kriteria menarik pada uji coba yang dilakukan (Aini et al., 2018; Kurniasari et al., 2018; Sutama et al., 2014). Keterbaruan yang terdapat pada penelitian ini dengan penelitian sebelumnya adalah bahwa modul pembelajaran matematika berbasis etnomatematika berbantuan Wingeom pada materi bangun ruang sisi lengkung memiliki kategori sangat menarik. 
Setelah tahap uji coba produk dilakukan tanpa adanya revisi. Tahapan selanjutnya yaitu uji coba pemakaian menggunakan tes untuk mengetahui efektivitas produk berupa soal uraian yang akan dibagikan kepada peserta didik, namun tidak bisa peneliti lakukan karena adanya wabah Coronavirus Disease (Covid-19) dimana pelaksanaan kegiatan pembelajaran dilaksanakan secara daring atau online sehingga untuk melakukan uji coba pemakaian tidak memungkinkan. Hal ini sesuai dengan Surat Edaran No.4 Tahun 2020 tentang Pelaksanaan Pendidikan dalam Masa Darurat Coronavirus Disease (Covid-19). Tahap ini juga diperkuat oleh peneliti sebelumnya yang menunjukkan bahwa pengembangan yang dilakukan memiliki kategori efektif (Arif et al., 2019; Fitriyah et al., 2018; Fonna 2018; Sutrisno \& Atira 2020; Hidayat 2016; Sefriyanti 2019). Selanjutnya peneliti menyebarluaskan produk ke media sosial melalui link yang peneliti sediakan. Hal ini bertujuan agar pengguna dari semua kalangan dapat mendapatkan modul dengan mudah. Tampilan modul pembelajaran matematika berbasis etnomatematika berbantuan Wingeom pada materi bangun ruang sisi lengkung disajikan pada Gambar 7.

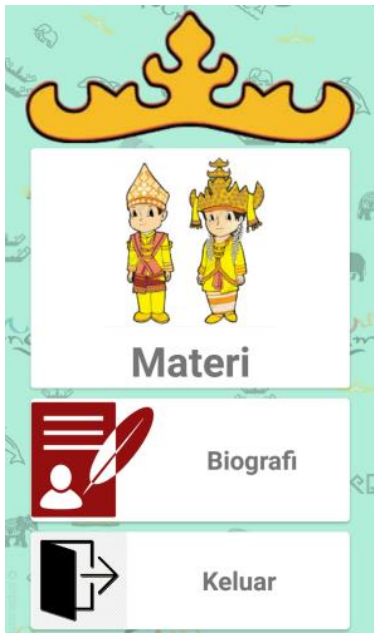

(a)

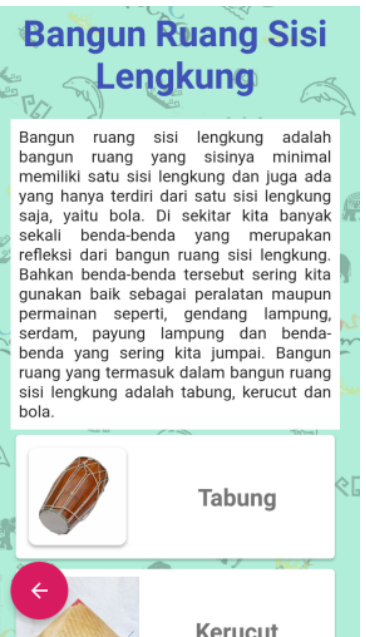

(b)

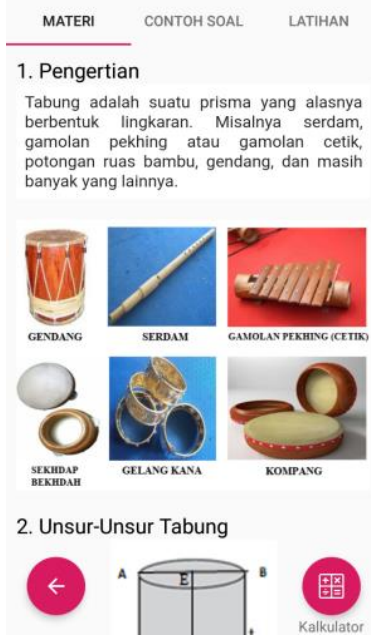

(c)

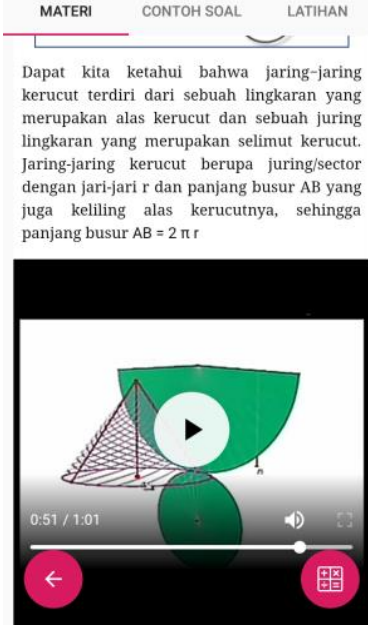

(d)

Gambar 7. Tampilan modul

\section{KESIMPULAN}

Berdasarkan dengan hasil penelitian yang dipaparkan pada pembahasan sebelumnya dapat ditarik kesimpulan bahwa pada penelitian ini menghasilkan sebuah modul pembelajaran berbasis etnomatematika berbantuan Wingeom pada materi bangun ruang sisi lengkung. Hasil uji kelayakan dinilai oleh para ahli yaitu dengan kriteria layak, ahli media dengan kriteria sangat layak, dan ahli bahasa memperoleh kriteria sangat layak. Dan pada uji coba produk memperoleh kriteria "Sangat Menarik" pada uji coba skala kecil. Pada uji coba produk dengan skala besar memperoleh kriteria "Sangat Menarik". Kesimpulan tersebut terdapat sebuah saran bahwa modul pembelajaran berbasis etnomatematika berbantuan Wingeom dapat dikembangkan dengan materi yang lebih luas. Kemudian modul pembelajaran berbasis etnomatematika berbantuan wingeom menyajikan materi bangun ruang sisi lengkung saja, sehingga perlu dikembangkan kembali pada materi yang lain, agar dapat memotivasi dan meningkatkan minat belajar peserta didik dalam proses prembelajaran secara aktif.

\section{REKOMENDASI}

Berdasarkan kesimpulan yang telah dijelaskan makan dapat mengajukan rekomendasi sebagai berikut: (1) modul pembelajaran matematika menyajikan materi bangun ruang sisi lengkung saja, sehingga perlu dikembangkan kembali pada materi yang lain; (2) bobot penyimpanan modul pembelajaran matematika cukup besar dikarenakan tampilan video yang terdapat di dalam modul secara offline; (3) Penggunaan modul pembelajaran matematika berbasis etnomatematika berbantuan wingeom pada materi bangun ruang sisi lengkung hanya dapat digunakan di 
smartphone android, sehingga modul tidak dapat digunakan di IOS (Iphone Operation System) dan PC, diharapkan modul dapat dikembangkan agar dapat digunakan disemua jenis smartphone.

\section{UCAPAN TERIMAKASIH}

Ucapan terimakasih sebesar-sebarnya kepada orang tua tercinta ayahanda Ridwan, S.Pd.I dan ibunda Enisah Tanjung yang selalu mendampingi setiap saat. Netriwati, M.Pd dan Bapak Komarudin M.Pd yang selalu membimbing dan memberikan saran kepada peneliti sehingga penelitian ini dapat terselesaikan. Tak lupa juga diucapkan kepada Bapak Dr. Nanang Supriadi, M. Sc dan Bapak Riski Wahyu Yunian Putra, M.Pd selaku Ketua Jurusan dan Sekretaris serta seluruh dosen Jurusan Pendidikan Matematika UIN Raden Intan Lampung. Kepada Anggun Mega Mentari, S.Pd dan Maratul Qiftiyah, S.Pd serta para senior yang tidak bisa disebutkan satu per satu. Terima kasih kami sampaikan kepada MTs.N 2 Bandar Lampung dan MTs Mathla'ul Anwar Gisting yang telah bersedia menjadi tempat penelitian dan membantu menyediakan tempat dan siswa-siswinya sebagai sampel pada penelitian ini.

\section{DAFTAR PUSTAKA}

Abdurohman, Endun, Muis, A., \& Sulistyono. (2020). Pembelajaran inquiri dalam meningkatkan keterampilan berpikir kritis dan retensi siswa pada materi pencemaran lingkungan. Edubiologica Jurnal Penelitian IImu dan Pendidikan Biologi, 7(2), 1-7.

Aini, Purnama, E., Masykur, R., \& Komarudin. (2018). Handout matematika berbantuan etnomatematika berbasis budaya lokal. Desimal: Jurnal Matematika, 1(1), 73. https://doi.org/10.24042/djm.v1i1.1950.

Amin \& Rifqi, A. (2015). Pengembangan pendidikan agama islam: reinterpretasi berbasis interdisipliner. Cetakan I. Sewon, Bantul, Yogyakarta: LKIS Pelangi Aksara.

Anas \& Sudijono. (2015). Pengantar statistik pendidikan. Jakarta Pusat: PT. Raja Grafindo.

Aprilianti, Indri, Sunardi, \& Yudianto, E. (2019). Etnomatematika pada aktivitas petani kakao desa temuasri sempu banyuwangi sebagai bahan ajar siswa. Saintifika 21(1), 1-8.

Arif, Fikri, D. S., Purnomo, D., \& Sutrisno. (2019). Pengembangan media pembelajaran interaktif berbasis etnomatematika berbantu macromedia flash. JKPM (Jurnal Kajian Pendidikan Matematika), 4(2), 89-100.

Cholik, M., \& Adinawan. 2015. Matematika semester 2 untuk SMP kelas ix. Jakarta: Erlangga.

Cicilia, Yayuk, \& Vebrianto, R. (2020). Survei penilaian Ikpd untuk meningkatkan pemahaman pada materi siklus makhluk hidup siswa sekolah dasar. Jurnal IImiah Pendidikan Guru Sekolah Dasar, 4(1), 83-94.

Diana, Mulia, Netriwati, \& Suri, F. I. (2018). Modul pembelajaran matematika bernuansa islami dengan pendekatan inkuiri. Desimal: Jurnal Matematika, 1(1), 7. https://doi.org/10.24042/djm.v1i1.1906.

Disnawati, Hermina, \& Nahak, S. (2019). Pengembangan lembar kerja siswa berbasis etnomatematika tenun timor pada materi pola bilangan. Jurnal Elemen, 5(1), 64-79.

Fajar, Alan, F., Sunardi, S., \& Yudianto, E. (2018). Etnomatematika pembuatan kerajinan tangan anyaman bambu masyarakat osing di desa gintangan banyuwangi sebagai bahan ajar geometri. KadikmA, 9(3), 97-108.

Firmasari, Siska, Y. L., Sukestiyarno, \& Mariani, S. (2013). Pengembangan bahan ajar menggunakan taksonomi solo superitem dengan tutor sebaya berbantuan wingeom. Unnes Journal of Mathematics Education Research, 2(1). 
Fitriyah, Nur, D., Santoso, S., \& Suryadinata, N. (2018). Bahan ajar transformasi geometri berbasis discovery learning melalui pendekatan etnomatematika. Jurnal Elemen, 4(2), 145-58.

Fonna, M., \& Mursalin. (2018). Pengembangan modul geometri analitik bidang berbantuan wingeom sofware untuk meningkatkan kemampuan representasi matematis. UNION: Jurnal Pendidikan Matematika, 6(3), 12.

Harista, Qomadza, A. Q., \& Rukun, K. (2020). Efektivitas pengembangan modul pembelajaran berbasis e-learning pada mata kuliah perawatan kulit wajah jurusan pendidikan tata rias dan kecantikan. Jurnal Imiah Pendidikan dan Pembelajaran, 4(1), 151-62.

Haryati, S. (2012). Research and development (r\&d) sebagai salah satu model penelitian dalam bidang pendidikan. FKIP-UTM 37 (01), 11-26.

Hasanah, Uzlifatul, \& Indrawati, D. (2020). Pengembangan modul gebar (gerak baris-berbaris) bagi siswa kelas iv sekolah dasar. Jurnal Penelitian Pendidikan Guru Sekolah Dasar, 7(7).

Hidayat, Saifullah, Anggraeni, F. D. R., \& Mukhlishoh, S. (2020). Pengembangan buku bergambar bertekstur dilengkapi teka-teki silang sebagai media pembelajaran biologi sub materi jaringan epitel kelas xi sma. Symbiotic: Journal of Biological Education and Science, 1(1), 15-24.

Hidayat, Y. (2016). Perbedaan hasil belajar, minat dan motivasi siswa kelas x sman 1 palu pada materi jarak titik ke bidang menggunakan model pembelajaran kooperatif tipe stad berbantuan e-learning dan aplikasi wingeom. JSTT, 5(1).

Hidayati, N. (2016). Pengembangan bahan ajar bahasa indonesia berbasis lingkungan hidup terintegrasi dalam pembelajaran membaca dan menulis teks siswa smp negeri 2 turen tahun 2015. Jurnal NOSI, 4(1), 68-80.

Irmayanti, Irmayanti, \& Suryani, H. (2020). Pengembangan modul aplikasi komputer terapan tata busana bagi mahasiswa PKK FT UNM. TEKNOBUGA: Jurnal Teknologi Busana dan Boga, 8(1), 38-48.

Khalimah, Nur, Farin, K. I., Nikmah, M. Ni'mah, K., \& Jatmiko. (2017). Budaya kediri dalam pembelajaran matematika (pengembangan lembar kegiatan siswa (lks) berbasis etnomatematika melalui pendekatan saintifik. JIPMat, 2(1).

Kurniasari, Intan, Rakhmawati, R., \& Fakhri, J. (2018). Pengembangan e-module bercirikan etnomatematika pada materi bangun ruang sisi datar. Indonesian Journal of Science and Mathematics Education, 1 (3), 227-35. https://doi.org/10.24042/ijsme.v1i3.3597.

Kurniawan. (2008). Mandiri mengasah kemampuan diri matematika untuk SMP/MTs kelas ix. Jakarta: Erlangga.

Laurens, T. (2010). Penjenjangan metakognisi siswa yang valid dan reliabilitas. Jurnal Pendidikan dan Pembelajaran (JPP), 17(2), 201-11.

Linda, K., \& Setia, B. (2011). Matematika untuk SMP dan MTs kelas ix. Pusat Kurikulum dan Perbukuan Kementerian Pendidikan Nasional.

Marsigit, Setiana, D. S., \& Hardiarti, S. (2018). Pengembangan pembelajaran matematika berbasis etnomatematika. In Prosiding Seminar Nasional Pendidikan Matematika Etnomatnesia.

Maryati \& Suparman. (2018). Analisis kebutuhan bahan ajar berbasis etnomatematika dalam pembelajaran matematika sekolah menengah pertama. Pendidikan Matematika Universitas Muhammadiyah Purworejo, 387. 
Mulyani, E. (2016). Pengaruh penggunaan model pembelajaran kooperatif tipe student facilitator and explaining terhadap pemahaman matematik peserta didik. JP3M (Jurnal Penelitian Pendidikan Dan Pengajaran Matematika), 2(1), 29-34.

Nelawati, Meriyati, Putra, R. W. Y., \& Simatupang, A. T. (2018). Pengembangan bahan ajar bercirikan etnomatematika suku komering materi bangun datar siswa sekolah dasar. Prosiding Seminar Nasional Matematika dan Pendidikan Matematika, 1 (2), 407-14.

Nisa, Choirun, \& Agung, Y. A. (2014). Pengembangan media pembelajaran berbasis ICT menggunakan multisim 10 simulations pada materi pelajaran teknik elektronika dasar di SMK negeri 7 surabaya. Jurnal Pendidikan Teknik Elektro, 3, 02.

Nugroho, Zaid, K. U., Widada, W., Zamzaili, \& Herawaty, D. (2019). Pemahaman konsep matematika melalui media youtube dengan pendekatan etnomatematika. Jurnal Pendidikan Matematika Raflesia, 4(1): 96-106.

Nuniek \& Agus, A. (2008). Mudah belajar matematika untuk kelas IX SMP/MTs. Jakarta: Pusat Perbukuan Departemen Pendidikan Nasional.

Nurafni, Atika, Pujiastuti, H., \& Mutaqin, A. (2020). Pengembangan bahan ajar trigonometri berbasis kearifan lokal. Journal of Medives: Journal of Mathematics Education IKIP Veteran Semarang, 4(1), 71-80.

Nurhayati, Y., Zakiah, N. E., \& Amam, A. (2020). Integrasi contextual teaching learning (ctl) dengan geogebra: dapatkah meningkatkan kemampuan koneksi matematis siswa?. Teorema: Teori dan Riset Matematika, 5(1), 27-34.

Prabawa, Ari, E., \& Zaenuri. (2017). Analisis kemampuan pemecahan masalah ditinjau dari gaya kognitif siswa pada model project based learning bernuansa etnomatematika. Unnes Journal of Mathematics Education Research, 6(1), 120-29.

Pradipta, Dyah, \& Hernawati, K. (2015). Pengembangan lembar kegiatan siswa materi garis dan sudut dengan pendekatan inquiry berbantuan software wingeom. Seminar Nasional Matematika dan Pendidikan Matematika UNY.

Prasetya \& Indra, T. (2012). Meningkatkan keterampilan menyusun instrumen hasil belajar berbasis modul interaktif bagi guru-guru ipa smpn kota magelang. Journal of Research and Educational Research Evaluation, 1(2).

Pratami, Martyas, R. K. V., Pratiwi, D. D., \& Muhassin, M. (2018). Pengembangan media pembelajaran matematika berbantu adobe flash melalui etnomatematika pada rumah adat lampung. NUMERICAL: Jurnal Matematika dan Pendidikan Matematika, 59-72.

Purwanto. (2007). Pengembangan Modul. Jakarta.

Pinahayu, R., Ajeng, E., Auliya, R. N., \& Adnyani, L. P. W. (2018). Implementasi aplikasi wingeom untuk pengembangan bahan ajar di smp. Jurnal PKM 01 (02).

Rizki \& Putra, W. Y. (2019). Pengembangan bahan ajar gamifikasi matematika siswa mts. Jurnal Penelitian dan Pembelajaran Matematika, 12(1).

Sani \& Abdullah, R. (2019). Pembelajaran berbasis hots edisi revisi: higher order thinking skills. Tira Smart, 1.

Saputra, Ady, Wakhinuddin, \& Rizal, F. (2019). Pengembangan media pembelajaran elektronik berbasis masalah pada mata pelajaran komputer dan jaringan dasar. Jurnal Pendidikan Teknologi Kejuruan, 2(2), 39-44.

Sari, Permata, R. S., Fadila, A., \& Fiteriani, I. (2018). Pengembangan bahan ajar matematika pada materi bangun ruang sisi datar menggunakan software adobe flash untuk kelas viii smp. Prosiding Seminar Nasional Matematika dan Pendidikan Matematika, 1, 565-72. 
Sedarmayanti, Hidayat, \& Syarifudin. (2002). Metode Penelitian. Bandung: Mandiri Maju.

Sefriyanti, D. (2019). Pengembangan media pembelajaran materi dimensi 2 dan 3 berbasis aplikasi wingeom di smkn 3 sijunjung. Jurnal Saintika Unpam: Jurnal Sains dan Matematika Unpam, 2(2), 124-35.

Serena, Anasthasia, N., Suarsini, E., \& Lukiati, B. (2020). Eksplorasi kebutuhan bahan ajar pada matakuliah bioprospeksi. Jurnal Pendidikan: Teori, Penelitian, dan Pengembangan, 5(4): 472-77.

Setiawan, Bara, T., Wahyu, S., \& Sunardi, S. (2018). Etnomatematika pada pura mandara giri semeru agung sebagai bahan pembelajaran matematika. KadikmA, 9(1), 156-64.

Setiyadi \& Wahyu, M. (2017). Pengembangan modul pembelajaran biologi berbasis pendekatan saintifik untuk meningkatkan hasil belajar siswa. Journal of Educational Science and Technology (EST), 3(2), 102-12.

Srimaya. (2017). Efektivitas media pembelajaran power point untuk meningkatkan motivasi dan hasil belajar biologi siswa. Jurnal Biotek, 5(1), 53-68.

Subchan, Winarni, Mufid, M. S., Fahim, K., \& Syaifudin, W. H. (2018). Matematika - Studi dan Pengajaran. Cetakan II. Jakarta: Kementerian Pendidikan dan Kebudayaan.

Subekti, Marfilinda, \& Suparman. (2020). Analisis kebutuhan e-lkpd untuk menstimulus kemampuan berpikir kritis dengan model pembelajaran discovery learning. Science, Technology, Engineering, Economics, Education, and Mathematics, 1(1).

Sukri, Akhmad, Harisanti, B. M., Wahyuni, B. S., Suharti, \& Amirudi, A. (2017). Uji validasi bahan ajar berbasis keunggulan lokal di sdn gili matra, lombok utara nusa tenggara barat. Jurnal Edukasi Matematika dan Sains, 5(2), 92-97.

Sutama, Ketut, I., Suharta, I. G. P, \& Suweken, G. (2014). Pengembangan pembelajaran geometri sma berdasarkan teori van hiele berbantuan wingeom. Jurnal Pendidikan dan Pembelajaran Matematika Indonesia, 3(1).

Sutrisno, Budi, A., \& Atira, A. (2020). Keefektifan penggunaan aplikasi wingeom dalam pemaparan materi pelajaran dimensi tiga. De Fermat: Jurnal Pendidikan Matematika, 3(1), 37-45.

Tjiptiany, Novita, E., As'ari, A. R., \& Muksar, M. (2016). Pengembangan modul pembelajaran matematika dengan pendekatan inkuiri untuk membantu siswa sma kelas $\mathrm{x}$ dalam memahami materi peluang. Jurnal Pendidikan: Teori, Penelitian, dan Pengembangan, 1(10): 1938-42.

Umam, M. K. (2019). Studi komparatif paradigma teori belajar konvensional barat dengan teori belajar islam. Jurnal Al-Hikmah, 7(2), 24.

Utami, R. E., Nugroho, A. A., Dwijayanti, I., \& Sukarno, A. (2018). Pengembangan e-modul berbasis etnomatematika untuk meningkatkan kemampuan pemecahan masalah. JNPM (Jurnal Nasional Pendidikan Matematika), 2(2), 268-83.

Wijayanto, Z. (2017). Pengembangan perangkat pembelajaran matematika berbasis etnomatematika pada keraton yogyakarta. SOSIOHUMANIORA: Jurnal IImiah IImu Sosial dan Humaniora, $3(1)$.

Yustiana, S., \& Kusumadewi, R. F. (2020). Pengembangan bahan ajar modul berbasis ctl sebagai bagian dari pengembangan ssp. Jurnal IImiah KONTEKSTUAL, 1(02), 1-6.

Zakiy, M. A.,, Syazali, M., \& Farida. (2018). Pengembangan media android dalam pembelajaran matematika. Triple $S$ (Journals of Mathematics Education), 1(2), 87-96. 